\title{
Nonvolatile voltage controlled molecular spin state switching
}

\author{
Cite as: Appl. Phys. Lett. 114, 032901 (2019); doi: 10.1063/1.5054909 \\ Submitted: 4 September 2018 - Accepted: 3 January 2019 • Published Online: \\ 22 January 2019
}

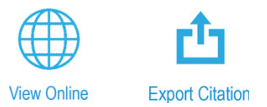

\section{G. Hao, ${ }^{1}$ (D) A. Mosey, ${ }^{2}$ X. Jiang, ${ }^{7}$ A. J. Yost, ${ }^{1}$ (D) K. R. Sapkota, ${ }^{3}$ G. T. Wang, ${ }^{3}$ (D) X. Zhang, ${ }^{4}$ (D) J. Zhang, ${ }^{4}$ (D) A. T. N'Diaye, ${ }^{5}$ R. Cheng, ${ }^{2}$ X. Xu, (D) and P. A. Dowben ${ }^{1, a)}$ (D)}

\author{
AFFILIATIONS \\ ${ }^{7}$ Department of Physics and Astronomy, University of Nebraska, Lincoln, Nebraska 68588-0299, USA \\ ${ }^{2}$ Physics Department, Indiana University Purdue University-Indianapolis, 402 N Blackford Str. LD154, Indianapolis, Indiana 46202, \\ USA \\ ${ }^{3}$ Advanced Materials Sciences, Sandia National Laboratories, Albuquerque, New Mexico 87185, USA \\ ${ }^{4}$ Department of Chemistry, University of Nebraska-Lincoln, 551 Hamilton Hall, Lincoln, Nebraska 68588-0304, USA \\ ${ }^{5}$ Advanced Light Source, Lawrence Berkeley National Laboratory, Berkeley, California 94720, USA \\ a) Electronic mail: pdowbent@unl.edu
}

\begin{abstract}
Voltage-controlled room temperature isothermal reversible spin crossover switching of $\left[\mathrm{Fe}\left\{\mathrm{H}_{2} \mathrm{~B}(\mathrm{pz})_{2}\right\}_{2}(\mathrm{bipy})\right]$ thin films is demonstrated. This isothermal switching is evident in thin film bilayer structures where the molecular spin crossover film is adjacent to a molecular ferroelectric. The adjacent molecular ferroelectric, either polyvinylidene fluoride hexafluoropropylene or croconic acid $\left(\mathrm{C}_{5} \mathrm{H}_{2} \mathrm{O}_{5}\right)$, appears to lock the spin crossover $\left[\mathrm{Fe}\left\{\mathrm{H}_{2} \mathrm{~B}(\mathrm{pz})_{2}\right\}_{2}\right.$ (bipy)] molecular complex largely in the low or high spin state depending on the direction of ferroelectric polarization. In both a planar two terminal diode structure and a transistor structure, the voltage controlled isothermal reversible spin crossover switching of $\left[\mathrm{Fe}\left\{\mathrm{H}_{2} \mathrm{~B}(\mathrm{pz})_{2}\right\}_{2}(\right.$ bipy) $]$ is accompanied by a resistance change and is seen to be nonvolatile, i.e., retained in the absence of an applied electric field. The result appears general, as the voltage controlled nonvolatile switching can be made to work with two different molecular ferroelectrics: croconic acid and polyvinylidene fluoride hexafluoropropylene.
\end{abstract}

Published under license by AIP Publishing. https://doi.org/10.1063/1.5054909

It has been frequently suggested that the spin crossover (SCO) phenomenon, in $3 d$ transition metal compounds, has potential applicability in molecular spintronic devices. ${ }^{1-14}$ For the spin crossover molecular systems to have functional utility, such as in molecular thin film memory devices, nonvolatility is required. Mechanisms are needed to lock the spin crossover molecular systems in a particular spin state and to change the molecular spin state (unlocking). Indeed, practical solid state devices, fabricated from the spin crossover molecular systems, require voltage controlled changes in the electronic structure at room temperature. The "write" operation needs to be accompanied by a read mechanism; this means that there is a property where the spin state is easily "sensed": for example, the spin state change is accompanied by a change in conductance. Conductance changes of the spin crossover molecular systems are well known, ${ }^{2,3,6-9,13,15-17}$ but if this is to be exploited in a device, then this should be for molecular films on a dielectric substrate, so that it is the spin crossover molecular system that dominates the device performance.

Isothermal changes in the electronic structure of the spin crossover molecular system have now been achieved for the $\mathrm{Fe}$ (II) spin crossover complex $\left[\mathrm{Fe}\left\{\mathrm{H}_{2} \mathrm{~B}(\mathrm{pz})_{2}\right\}_{2}(\mathrm{bipy})\right]^{13,14}\left[\mathrm{Fe}(\mathrm{trz})_{3}\right]\left(\mathrm{BF}_{4}\right)_{2}$ $($ trz $=$ triazole $)],{ }^{9} \quad\left[\mathrm{Fe}(\text { phen })_{2}(\mathrm{NCS})_{2}\right],{ }^{8} \quad\left\{\mathrm{Rb}_{0.8} \mathrm{Mn}\left[\mathrm{Fe}(\mathrm{CN})_{6}\right]_{0.93}\right.$. $\left.1.62 \mathrm{H}_{2} \mathrm{O}\right\},{ }^{6}$ and $\left[\mathrm{Fe}(\mathrm{bpz})_{2}(\mathrm{phen})\right]$, but the latter was observed at $5 \mathrm{~K}^{3}$ not at room temperature. Similarly, voltage control of $\left[\mathrm{Co}\left(\mathrm{III}(\mathrm{dpzca})_{2}\right]^{+}\right.$has also been observed. ${ }^{17}$ It has now been demonstrated that $\left[\mathrm{Fe}\left\{\mathrm{H}_{2} \mathrm{~B}(\mathrm{pz})_{2}\right\}_{2}(\right.$ bipy)], where $\mathrm{pz}=$ tris(pyrazol-1-yl)borohydride and bipy = 2,2'-bipyridine, can be locked in the low spin (LS) state by a dielectric substrate and excited into the high spin (HS) state at room temperature by an X-ray fluence and then relaxed back to the low spin state either thermally ${ }^{14}$ or through magnetic field switching, ${ }^{17}$ in the vicinity of room temperature. This locking of a spin crossover complex, largely in the low spin state when placed on dielectric substrates, 
seems to be a general result for $\left[\mathrm{Fe}\left\{\mathrm{H}_{2} \mathrm{~B}(\mathrm{pz})_{2}\right\}_{2}\right.$ (bipy) $]$. $^{13,14,18}$ One exception to a dielectric substrate locking spin crossover complexes in the low spin state is for $\left[\mathrm{Fe}\left\{\mathrm{H}_{2} \mathrm{~B}(\mathrm{pz})_{2}\right\}_{2}\right.$ (bipy)] on the dielectric ferroelectric polyvinylidene-fluoride when $\left[\mathrm{Fe}\left\{\mathrm{H}_{2} \mathrm{~B}(\mathrm{pz})_{2}\right\}_{2}\right.$ (bipy) $]$ adopts the high spin configuration when deposited on polyvinylidene-fluoride (PVDF) when the ferroelectric domain polarization points towards the spin crossover complex. $^{19}$

The isothermal switching of the molecular spin state appears to require an insulating substrate, ${ }^{13,14,18}$ consistent with the observation of the scanning tunneling microscopy (STM) tip manipulation of the spin state of $\mathrm{Fe}(1,10 \text {-phenanthroline })_{2}(\mathrm{NCS})_{2}$ on a dielectric substrate like $\mathrm{CuN}^{8}{ }^{8}$ In addition, voltage-control of the molecular spin state has been compellingly demonstrated, ${ }^{3,6,8,9,17}$ although at room temperature, nonvolatile spin state switching has not been conclusively demonstrated. A transition induced by the boundary layer with a ferroelectric on a spin crossover molecular complex like $\left[\mathrm{Fe}\left\{\mathrm{H}_{2} \mathrm{~B}(\mathrm{pz})_{2}\right\}_{2}\right.$ (bipy)] is expected to be nonvolatile, ${ }^{19}$ especially because charge displacement has been implicated in establishing the spin state. ${ }^{14}$

The expectation that room temperature nonvolatile voltage-controlled switching of the spin state is possible, not just for an individual molecule but an entire thin film, is further suggested by results that indicate the choice of ferroelectric polarization of the molecular ferroelectric polyvinylidene-fluoride will lock $\left[\mathrm{Fe}\left\{\mathrm{H}_{2} \mathrm{~B}(\mathrm{pz})_{2}\right\}_{2}\right.$ (bipy)] either in the high spin state or in the low spin state at room temperature. ${ }^{19}$ Here, in this work, we exploit the spin state switching of $\left[\mathrm{Fe}\left\{\mathrm{H}_{2} \mathrm{~B}(\mathrm{pz})_{2}\right\}_{2}(\mathrm{bipy})\right]^{14,19}$ in combination with several molecular ferroelectrics, including a variation of ferroelectric polyvinylidene-fluoride ${ }^{19}$ (here, polyvinylidene fluoride hexafluoropropylene or PVDF-HFP) as well as croconic acid (4,5-dihydroxycyclopentenetrione, i.e., $\left.\mathrm{C}_{5} \mathrm{H}_{2} \mathrm{O}_{5}\right)^{20}$ These molecular thin film combinations provide a demonstration

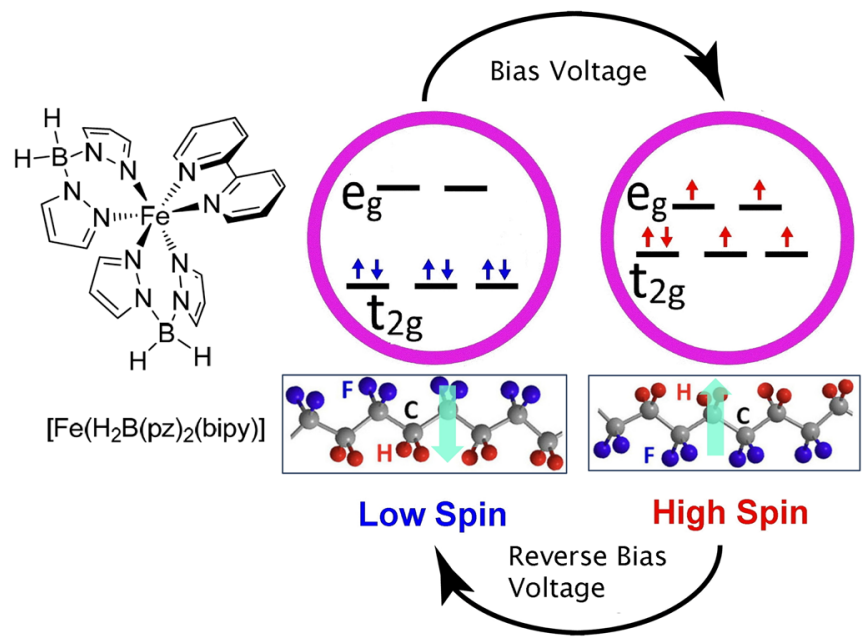

FIG. 1. The schematic structure of $\left[\mathrm{Fe}\left\{\mathrm{H}_{2} \mathrm{~B}(\mathrm{pz})_{2}\right\}_{2}\right.$ (bipy)], at the left. The schematics of reversible voltage-control of the spin state of $\left[\mathrm{Fe}\left\{\mathrm{H}_{2} \mathrm{~B}(\mathrm{pz})_{2}\right\}_{2}\right.$ (bipy)] thin films on PVDF-HFP ferroelectric substrates. [Fe $\left\{\mathrm{H}_{2} \mathrm{~B}(\mathrm{pz})_{2}\right\}_{2}$ (bipy)] is pinned, in the majority, in the low spin (LS) state when ferroelectric polarization is directed away from $\left[\mathrm{Fe}\left\{\mathrm{H}_{2} \mathrm{~B}(\mathrm{pz})_{2}\right\}_{2}\right.$ (bipy)] and switches to the high spin (HS) state when ferroelectric polarization is directed towards $\left[\mathrm{Fe}\left\{\mathrm{H}_{2} \mathrm{~B}(\mathrm{pz})_{2}\right\}_{2}\right.$ (bipy)], as indicated, at the right. that voltage mediated interface interactions can be used to achieve the desired nonvolatile room-temperature switching of the spin state, as indicated in Fig. 1. Nonvolatility arises from the interface with nonconducting ferroelectrics.

$\left[\mathrm{Fe}\left\{\mathrm{H}_{2} \mathrm{~B}(\mathrm{pz})_{2}\right\}_{2}(\mathrm{bipy})\right]$, schematically illustrated in Fig. 1, was synthesized according to the literature. ${ }^{21,22}$ The spin crossover transition temperature of the resulting powder, measured by magnetometry, was found to be about $160 \mathrm{~K}$, in agreement with previous work. $^{19,22-27}$ This temperature dependent spin crossover transition, for $\left[\mathrm{Fe}\left\{\mathrm{H}_{2} \mathrm{~B}(\mathrm{pz})_{2}\right\}_{2}\right.$ (bipy)], is also evident in X-ray absorption, as indicated in Fig. 2(a). This charge neutral molecule was thermally evaporated to form a molecular thin film on either croconic acid or adjacent to polyvinylidene fluoride hexafluoropropylene (PVDF-HFP) substrates. For the samples with a PVDFHFP molecular ferroelectric layer, a $65 \mathrm{~nm}\left[\mathrm{Fe}\left\{\mathrm{H}_{2} \mathrm{~B}(\mathrm{pz})_{2}\right\}_{2}\right.$ (bipy)] spin crossover molecular thin film was deposited on top of preprinted interdigitated gold electrodes with a separation spacing of $10 \mu \mathrm{m} .20 \mathrm{~nm}$ (40 monolayers) of PVDF-HFP was then deposited on top of the spin crossover compound using the layer by layer Langmuir-Schaefer technique as outlined elsewhere. ${ }^{28}$ Essentially, this is a top and bottom gated transistor structure, as indicated in Fig. 3(b). A single ferroelectric domain, perpendicular to the plane, was achieved using an electric field $(\sim 300 \mathrm{MV} / \mathrm{m})$ applied perpendicular to the PVDF-HFP layer or about 3 times the coercive field of PVDF-HFP for this structure $[\sim 100 \mathrm{MV} / \mathrm{m}$, which is about $2-3 \mathrm{~V}$ for this structure, as seen in Fig. 3(c)]. For the conductance measurements, the electric field was applied in-plane, at less than $0.2 \mathrm{MV} / \mathrm{m}$ or much smaller than the coercive field of the ferroelectric polymer. All applied voltage and current measurements are d.c.

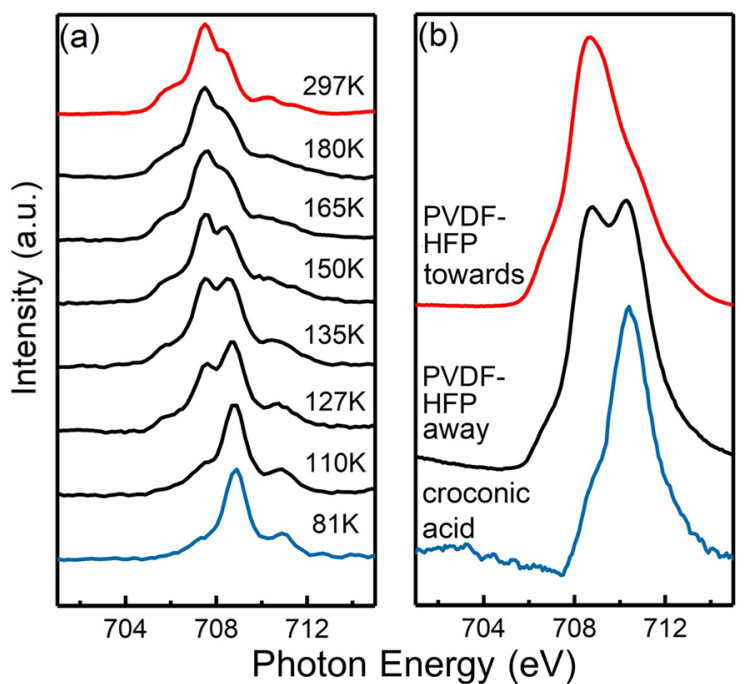

FIG. 2. The thermal spin crossover transition (a) compared to the voltage-control of the spin state of $\left[\mathrm{Fe}\left\{\mathrm{H}_{2} \mathrm{~B}(\mathrm{pz})_{2}\right\}_{2}\right.$ (bipy)] thin films on PVDF-HFP ferroelectric substrates (b). The X-ray absorption spectra indicate that $\left[\mathrm{Fe}\left\{\mathrm{H}_{2} \mathrm{~B}(\mathrm{pz})_{2}\right\}_{2}(\mathrm{bipy})\right]$ is mostly pinned in the low spin (LS) state when the ferroelectric polarization of PVDF-HFP is directed away from $\left[\mathrm{Fe}\left\{\mathrm{H}_{2} \mathrm{~B}(\mathrm{pz})_{2}\right\}_{2}\right.$ (bipy)] (PVDF-HFP away) and switches to the high spin (HS) state when the ferroelectric polarization of PVDF-HFP is directed towards $\left[\mathrm{Fe}\left\{\mathrm{H}_{2} \mathrm{~B}(\mathrm{pz})_{2}\right\}_{2}\right.$ (bipy)] (PVDF-HFP towards). [ $\mathrm{Fe}\left\{\mathrm{H}_{2} \mathrm{~B}(\mathrm{pz})_{2}\right\}_{2}($ bipy)] on croconic acid remains in the low spin state, in the absence of an applied voltage (croconic acid). 


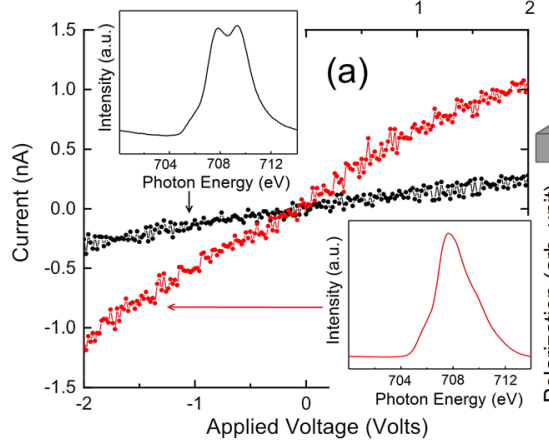

(b)

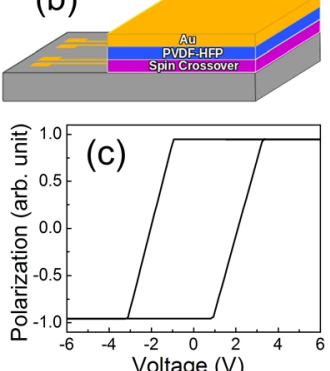

FIG. 3. The switching of conductance for $\left[\mathrm{Fe}\left\{\mathrm{H}_{2} \mathrm{~B}(\mathrm{pz})_{2}\right\}_{2}(\right.$ bipy $\left.)\right]$ on PVDF-HFP (a), for a transistor structure (b). $\left[\mathrm{Fe}\left\{\mathrm{H}_{2} \mathrm{~B}(\mathrm{pz})_{2}\right\}_{2}(\mathrm{bipy})\right]$ is pinned mostly in the low spin (LS) state when the ferroelectric polarization of PVDF-HFP is directed away from $\left[\mathrm{Fe}\left\{\mathrm{H}_{2} \mathrm{~B}(\mathrm{pz})_{2}\right\}_{2}\right.$ (bipy)] (PVDF away), as evident in X-ray absorption (spectrum "PVDF away"), leading to low conductance (black). $\left[\mathrm{Fe}\left\{\mathrm{H}_{2} \mathrm{~B}(\mathrm{pz})_{2}\right\}_{2}(\mathrm{bipy})\right]$ is pinned in the high spin (HS) state when the PVDF-HFP ferroelectric polarization is directed towards $\left[\mathrm{Fe}\left\{\mathrm{H}_{2} \mathrm{~B}(\mathrm{pz})_{2}\right\}_{2}(\mathrm{bipy})\right]$ (red), as also evident in the X-ray absorption (spectrum "PVDF towards"), leading to higher conductance. The hysteresis loop for the PVDF-HFP, perpendicular to the plane, as applies here, is shown in (c).

In the second type of sample structure studied, $20 \mathrm{~nm}$ $\left[\mathrm{Fe}\left\{\mathrm{H}_{2} \mathrm{~B}(\mathrm{pz})_{2}\right\}_{2}\right.$ (bipy)] thin films were deposited on top of $200 \mathrm{~nm}$ thick croconic acid thin films grown by physical vapor deposition and deposited on silicon oxide substrates with preprinted gold electrodes and interdigitated gold electrodes with gaps of $260 \mathrm{~nm}$, as shown in Fig. 4. Due to the roughness of the croconic acid layer, this device structure is essentially a two-terminal diode/capacitor like structure. Here, the electrodes were fabricated by electron beam lithography (EBL) and the lift-off process. Electron beam lithography was performed to define the electrode-patterns. In the final product, the measured width and gap between the electrodes were $10 \mu \mathrm{m}$ and $260 \mathrm{~nm}$, respectively.

X-ray diffraction, ${ }^{29,30}$ Mossbauer spectroscopy, ${ }^{24}$ scanning tunneling microscopy, ${ }^{10,22} \mathrm{X}$-ray photoemission, ${ }^{23}$ inverse photoemission, ${ }^{19,27}$ X-ray absorption, ${ }^{14,18,19,26,30}$ and of course

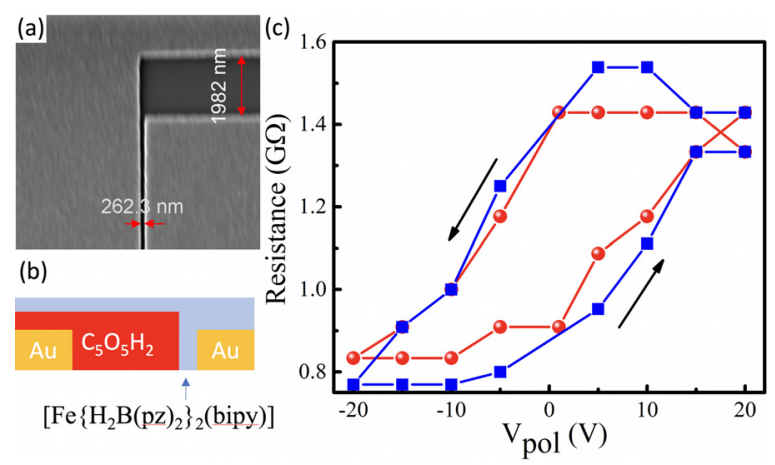

FIG. 4. (a) The scanning electron microscopy image of the substrate, with $\mathrm{Au}$ electrodes. (b) The schematic structure of junctions in the device of $20 \mathrm{~nm}$ $\left[\mathrm{Fe}\left\{\mathrm{H}_{2} \mathrm{~B}(\mathrm{pz})_{2}\right\}_{2}\right.$ (bipy)] deposited on top of $200 \mathrm{~nm}$ thick croconic acid on the substrate in (a). (c) Resistance of the device measured at $1 \mathrm{~V}$ (less than the coercive voltage for ferroelectric switching of this croconic acid film at room temperature), after applying a poling voltage $\left(\mathrm{V}_{\mathrm{pol}}\right)$ displayed as the horizontal voltage at room temperature. Two successive loops are shown, first red and then blue, indicating reproducibility. magnetometry ${ }^{19,22-27,30}$ have all been used successfully to determine the spin state of $\left[\mathrm{Fe}\left\{\mathrm{H}_{2} \mathrm{~B}(\mathrm{pz})_{2}\right\}_{2}\right.$ (bipy)]. X-ray absorption spectroscopy has the advantage of rapidity, distinct signature of the low spin state (Fig. 2, the spectrum in blue) and the high spin state (Fig. 2, the spectrum in red), and provides a facile means for interpolation between these two benchmark spectra, to assess the extent of the high spin state and the low spin state, when the spectra have contributions from both spin states. The X-ray absorption spectroscopy (XAS) measurements were performed at the bending magnet beamline 6.3.1, at the Advanced Light Source at Lawrence Berkeley National Laboratory. The photon flux was on the order of $10^{11}$ photons $/ \mathrm{sec} / 0.1 \% \mathrm{BW},{ }^{31}$ as in our previous studies. ${ }^{14,18}$ The experiments, shown in Fig. 2(b), were all carried out at room temperature. Circularly polarized $\mathrm{X}$-rays, with positive helicity, were used. The total electron yield (TEY) mode was used to measure the absorption of the Fe $\mathrm{L}_{3}$ edge, making the measurements relatively surface sensitive, but because of the dielectric characteristics of the ferroelectric thin films used here, this also means that the X-ray absorption measurements are perturbed by changes in photohole screening, requiring recalibration of the X-ray absorption spectra energies by about $1 \mathrm{eV}$. Another problem faced in these specific X-ray absorption experiments is that the X-rays initiate a spin state change for $\left[\mathrm{Fe}\left\{\mathrm{H}_{2} \mathrm{~B}(\mathrm{pz})_{2}\right\}_{2}\right.$ (bipy)] on many dielectric substrates, as discussed elsewhere. ${ }^{14,18}$ This means that X-ray absorption data must be acquired rapidly, so as to avoid having the measured spin state occupancy strongly affected by the measurement process. In the case of the thin film studies, reported here, the need for rapid data acquisition means that the XAS spectra have degraded resolution. We acquired an $\mathrm{L}_{3}$-edge spectrum in about $15 \mathrm{~s}$.

In the low spin state of $\left[\mathrm{Fe}\left\{\mathrm{H}_{2} \mathrm{~B}(\mathrm{pz})_{2}\right\}_{2}(\mathrm{bipy})\right]$, well below $160 \mathrm{~K}, 14,18,19,25$ the $3 d$ electrons occupy the $t_{2 \mathrm{~g}}$ orbitals in pairs leaving the $\mathrm{e}_{\mathrm{g}}$ orbitals empty. This is observable in the $2 \mathrm{p}_{3 / 2}$ (Fe $\mathrm{L}_{3}$ ) X-ray absorption spectra as a major e $\mathrm{e}_{\mathrm{g}}$ peak at about $709 \mathrm{eV}$ [Fig. 2(a), blue]. In the high spin state, the $e_{g}$ orbitals are partially populated with the $t_{2 g}$ orbitals subsequently partly depopulated, which corresponds in the XAS spectra at the Fe $\mathrm{L}_{3}\left(2 \mathrm{p}_{3 / 2}\right)$ edge to a decrease in the peak intensity at $709 \mathrm{eV}$ and an increase in the corresponding $t_{2 \mathrm{~g}}$ shoulder at about $706.5 \mathrm{eV}$ and a peak at $708 \mathrm{eV}$ [Fig. 2(a), red]. ${ }^{14,18,19,25}$ The spectra of the low spin state (Fig. 2, the spectrum in blue) and the high spin state (Fig. 2, the spectrum in red), from the temperature dependent spin crossover transition, are good "fingerprints" of the spin state as noted above and can be used to infer the percentage of high spin and low spin state occupancy.

Previous studies ${ }^{19}$ have shown that the spin state of films of $\left[\mathrm{Fe}\left\{\mathrm{H}_{2} \mathrm{~B}(\mathrm{pz})_{2}\right\}_{2}(\mathrm{bipy})\right], 10-25$ molecules thick, on poled polyvinylidene fluoride-trifluoroethylene (PVDF) retains a majority of the low spin state when ferroelectric polarization is directed away from $\left[\mathrm{Fe}\left\{\mathrm{H}_{2} \mathrm{~B}(\mathrm{pz})_{2}\right\}_{2}\right.$ (bipy)] (PVDF-HFP away) and switches to the high spin state when ferroelectric polarization is directed towards $\left[\mathrm{Fe}\left\{\mathrm{H}_{2} \mathrm{~B}(\mathrm{pz})_{2}\right\}_{2}\right.$ (bipy)] (PVDF-HFP towards). There is now evidence for nonvolatile isothermal voltage-controlled switching of $65 \mathrm{~nm}$ [Fe $\left\{\mathrm{H}_{2} \mathrm{~B}(\mathrm{pz})_{2}\right\}_{2}$ (bipy)], placed adjacent to PVDF-HFP, as schematically indicated in Fig. 1 . This is evident in the X-ray absorption spectra of $\left[\mathrm{Fe}\left\{\mathrm{H}_{2} \mathrm{~B}(\mathrm{pz})_{2}\right\}_{2}(\mathrm{bipy})\right]$, when adjacent to PVDF-HFP, taken at room temperature, as seen in Fig. 2(b). 
We observe that with the ferroelectric polarization directed away from $\left[\mathrm{Fe}\left\{\mathrm{H}_{2} \mathrm{~B}(\mathrm{pz})_{2}\right\}_{2}\right.$ (bipy)], the ferroelectric locking of the low spin state is imperfect. There is some contribution of the high spin state occupancy observed in the X-ray absorption, not suggested in previous work of $\left[\mathrm{Fe}\left\{\mathrm{H}_{2} \mathrm{~B}(\mathrm{pz})_{2}\right\}_{2}\right.$ (bipy)] on PVDF. ${ }^{19}$ We need to consider that the $\left[\mathrm{Fe}\left\{\mathrm{H}_{2} \mathrm{~B}(\mathrm{pz})_{2}\right\}_{2}\right.$ (bipy)] thin film may be insufficiently thin in places. Previous work ${ }^{19}$ indicates that ferroelectrically poled polyvinylidene fluoride will typically only pin 20-25 molecular layers of [ $\mathrm{Fe}\left\{\mathrm{H}_{2} \mathrm{~B}(\mathrm{pz})_{2}\right\}_{2}$ (bipy)], in the low or high spin state. Thus, excess $\left[\mathrm{Fe}\left\{\mathrm{H}_{2} \mathrm{~B}(\mathrm{pz})_{2}\right\}_{2}\right.$ (bipy)], in this case, a film thickness in the region of 25-40 layers, cannot reasonably be expected to be fully pinned in the low spin state by the ferroelectric interface. Effectively, the excess $\left[\mathrm{Fe}\left\{\mathrm{H}_{2} \mathrm{~B}(\mathrm{pz})_{2}\right\}_{2}(\right.$ bipy $\left.)\right]$ would lead to contributions of a high spin state component to the X-ray absorption spectra of Fig. 2(b) (PVDF away), as no longer would all of the spin crossover molecular complex be locked in the low spin state by the molecular ferroelectric substrate. On the other hand, $\left[\mathrm{Fe}\left\{\mathrm{H}_{2} \mathrm{~B}(\mathrm{pz})_{2}\right\}_{2}\right.$ (bipy)] switches fully to the high spin (HS) state when ferroelectric polarization is directed towards $\left[\mathrm{Fe}\left\{\mathrm{H}_{2} \mathrm{~B}(\mathrm{pz})_{2}\right\}_{2}\right.$ (bipy)]. For films of $\left[\mathrm{Fe}\left\{\mathrm{H}_{2} \mathrm{~B}(\mathrm{pz})_{2}\right\}_{2}(\right.$ bipy) $]$, greater than 25 molecular layers thick, spin state bistability cannot be excluded. ${ }^{30}$ Nonetheless, it is clear that once set by the applied voltage, the majority of the high spin state or low spin state is retained in the zero applied field, when the spectra of Fig. 2(b) were taken. Because ferroelectric polarization is nonvolatile, the voltage switching of the spin state is also nonvolatile.

The longitudinal conductance changes of $\left[\mathrm{Fe}\left\{\mathrm{H}_{2} \mathrm{~B}(\mathrm{pz})_{2}\right\}_{2}\right.$ (bipy)] thin films on PVDF-HFP ferroelectric substrates are also nonvolatile, as indicated in Fig. 3. This conductance change, as summarized in Fig. 3, follows changes in the ferroelectric polarization made by the electric field applied between a bottom gate and a removable top gate electrode. This conductance change is significant in spite of the fact that the change from the high spin state to the low spin state is incomplete, as noted above. Because longitudinal conductance changes of $\left[\mathrm{Fe}\left\{\mathrm{H}_{2} \mathrm{~B}(\mathrm{pz})_{2}\right\}_{2}\right.$ (bipy)] thin films on PVDF-HFP ferroelectric substrates are also nonvolatile, this permitted the confirmation of the spin state by X-ray absorption experiments, as indicated in Fig. 3.

Nonvolatile voltage-controlled switching of the spin state is evident for $\left[\mathrm{Fe}\left\{\mathrm{H}_{2} \mathrm{~B}(\mathrm{pz})_{2}\right\}_{2}\right.$ (bipy)] thin films deposited on ferroelectric croconic acid thin films as well. The spin state of $20 \mathrm{~nm}$ $\left[\mathrm{Fe}\left\{\mathrm{H}_{2} \mathrm{~B}(\mathrm{pz})_{2}\right\}_{2}\right.$ (bipy)] thin films, as deposited on top of $200 \mathrm{~nm}$ thick croconic acid thin films, is largely in the low spin state, as indicated by the X-ray absorption spectrum in Fig. 2(b) (the spectrum labeled "croconic acid"). The nonvolatile switching between two resistance states is evident in the conductance, as seen in Fig. 4(c). The resistance switching is reproducible, as indicated, and follows the expected ferroelectric switching of croconic acid, ${ }^{20}$ where the coercive voltages seen here $(6-9 \mathrm{~V})$ are found to be similar to previous results (about $4 \mathrm{~V}$ ). ${ }^{21}$ The voltage-controlled switching of the spin state cannot be followed with X-ray absorption measurements, because the synchrotron beam spot size is $180 \mu \mathrm{m} \times 80 \mu \mathrm{m}$ while the gap between electrodes is $260 \mathrm{~nm}$. We cannot, therefore, provide accompanying proof from $\mathrm{X}$-ray absorption as to any change in the molecular spin state. Yet, given the symmetry of the device structure, there should be no resistance change with ferroelectric domain reversal, if changes in the spin state (and hence resistance) of the $\left[\mathrm{Fe}\left\{\mathrm{H}_{2} \mathrm{~B}(\mathrm{pz})_{2}\right\}_{2}\right.$ (bipy)] thin film are excluded.

This influence of the ferroelectric interface upon a spin crossover complex allows the interdigitated $\left[\mathrm{Fe}\left\{\mathrm{H}_{2} \mathrm{~B}(\mathrm{pz})_{2}\right\}_{2}\right.$ (bipy)] to be influenced by croconic acid. The non-volatile change in resistance in Fig. 4(c) is much smaller than expected from the conductance change seen for $\left[\mathrm{Fe}\left\{\mathrm{H}_{2} \mathrm{~B}(\mathrm{pz})_{2}\right\}_{2}(\mathrm{bipy})\right]$ thin films on PVDF-HFP ferroelectric substrates. Nonetheless, switching of the spin state, for at least a partial volume of the $\left[\mathrm{Fe}\left\{\mathrm{H}_{2} \mathrm{~B}(\mathrm{pz})_{2}\right\}_{2}\right.$ (bipy)] thin film, leads to a different resistance state, which is retained after the applied voltage is removed. The voltage-controlled switching of the $\left[\mathrm{Fe}\left\{\mathrm{H}_{2} \mathrm{~B}(\mathrm{pz})_{2}\right\}_{2}(\mathrm{bipy})\right] /$ croconic acid bilayer is very reproducible [Fig. 4(c)]. Similar bistability in conductance was observed with the Fe(II) coordination polymer $\left[\mathrm{Fe}(\operatorname{trz})_{3}\right]\left(\mathrm{BF}_{4}\right)_{2}(\operatorname{trz}=$ triazole), placed in between two $150 \mathrm{~nm}$ spaced electrodes, and voltage controlled switching observed at $340 \mathrm{~K}^{9}$ as well as for $\mathrm{Rb}_{0.8} \mathrm{Mn}\left[\mathrm{Fe}(\mathrm{CN})_{6}\right]_{0.93} \cdot 1.62 \mathrm{H}_{2} \mathrm{O}$, but without evidence that the device was nonvolatile. Similarly, the voltage-controlled switching of $\left[\mathrm{Fe}(\mathrm{phen})_{2}(\mathrm{NCS})_{2}\right]$ deposited on CuN, using an STM tip, also found that the high spin state has higher conductance, but again no evidence of nonvolatility was presented. $^{8}$

While the ferroelectric polarization of croconic acid is inplane here, in these two terminal measurements, the switching of the $\left[\mathrm{Fe}\left\{\mathrm{H}_{2} \mathrm{~B}(\mathrm{pz})_{2}\right\}_{2}\right.$ (bipy)] spin state depends on the roughness of the croconic acid layer. The croconic acid layer, as deposited here, is quite rough ${ }^{20}$ compared to Langmuir Blodgett deposited PVDF. ${ }^{32}$ In additional experiments, we find that with very small gaps, of $150 \mathrm{~nm}$, voltage controlled switching of the conductance, associated with the change in the spin state of $\left[\mathrm{Fe}\left\{\mathrm{H}_{2} \mathrm{~B}(\mathrm{pz})_{2}\right\}_{2}(\right.$ bipy) $]$, occurs at voltages much higher than the coercive voltage of croconic acid $\left(15 \mathrm{~V}\right.$ as compared to $\left.6-10 \mathrm{~V}^{20}\right)$. The retention of the voltage controlled resistance switching of $\left[\mathrm{Fe}\left\{\mathrm{H}_{2} \mathrm{~B}(\mathrm{pz})_{2}\right\}_{2}\right.$ (bipy)] was lost at zero bias (supplementary material), consistent with previous results. ${ }^{6,8,9}$ This points to the difficulties in constructing a device with smaller gaps between electrodes, where the ferroelectric croconic acid no longer locks the $\left[\mathrm{Fe}\left\{\mathrm{H}_{2} \mathrm{~B}(\mathrm{pz})_{2}\right\}_{2}(\right.$ bipy) $]$ spin state in the absence of an applied voltage. The absence of small amounts of polarization canting and diminished roughness on the scale of the gap between electrodes is implicated.

The mechanism for the higher conductance of $\left[\mathrm{Fe}\left\{\mathrm{H}_{2} \mathrm{~B}(\mathrm{pz})_{2}\right\}_{2}(\right.$ bipy $\left.)\right]$ thin films in the high spin state as compared to the conductance in the low spin state has not been directly determined from these measurements. It is known that the difference between the highest occupied molecular orbital and the lowest unoccupied molecular orbital is much larger (by about $2 \mathrm{eV}^{19}$ ) for the low spin state compared to the high spin state of $\left[\mathrm{Fe}\left\{\mathrm{H}_{2} \mathrm{~B}(\mathrm{pz})_{2}\right\}_{2}\right.$ (bipy)]. A smaller band gap for the high spin state of $\left[\mathrm{Fe}\left\{\mathrm{H}_{2} \mathrm{~B}(\mathrm{pz})_{2}\right\}_{2}\right.$ (bipy)] is consistent with higher conductance observed. For the spin crossover complex [Fe(bpz) $)_{2}$ phen], ${ }^{3}$ Fe(trans bis(3-(2-pyridyl)(1,2,3)triazolo(1-5)pyridine)bis(isothiocyanato) $,^{2} \mathrm{Rb}_{0.8} \mathrm{Mn}\left[\mathrm{Fe}(\mathrm{CN})_{6}\right]_{0.93} \cdot 1.62 \mathrm{H}_{2} \mathrm{O},{ }^{6}$ and $\left[\mathrm{Fe}(\mathrm{phen})_{2}(\mathrm{NCS})_{2}\right],{ }^{8}$ higher conductance was also seen for the high spin state. On the other hand, $\left[\mathrm{Fe}(\mathrm{Htrz})_{2}(\operatorname{trz})\right]\left(\mathrm{BF}_{4}\right){ }^{11}$ $\left[\mathrm{Fe}(\mathrm{PM}-\mathrm{AzA})_{2}(\mathrm{NCS})_{2}\right],{ }^{26}$ and $\left[\mathrm{Fe}\left(\mathrm{HB}(\mathrm{pz})_{3}\right)_{2}\right]^{7}$ were observed to 
have much higher conductance in the low spin state as compared to the high spin state. We can relate the change in the spin state to changes in the conductance for $\left[\mathrm{Fe}\left\{\mathrm{H}_{2} \mathrm{~B}(\mathrm{pz})_{2}\right\}_{2}(\mathrm{bipy})\right]$ thin films very clearly for $\left[\mathrm{Fe}\left\{\mathrm{H}_{2} \mathrm{~B}(\mathrm{pz})_{2}\right\}_{2}\right.$ (bipy)] on the PVDF-HFP ferroelectric co-polymer thin film. It is now clear that fabrication of molecular multiferroic devices is indeed possible.

The significance of this study is that this provides evidence of nonvolatile isothermal electrical switching of an Fe (II) spin crossover complex at room temperature, when the molecules are combined with a suitable ferroelectric. This voltage-controlled switching of the spin state is accompanied by a conductance change and can be engineered to be nonvolatile. There is now clear evidence that a molecular multiferroic is possible. The use of these two very different molecular ferroelectrics demonstrates the generality of the interaction between ferroelectrics and spin crossover molecules, but a different fabrication process is needed for different types of device structures, as the routes to forming the molecular ferroelectric thin film are different.

See supplementary material for resistance changes, with applied voltage, of a $20 \mathrm{~nm}\left[\mathrm{Fe}\left\{\mathrm{H}_{2} \mathrm{~B}(\mathrm{pz})_{2}\right\}_{2}\right.$ (bipy)] thin film deposited on top of a $200 \mathrm{~nm}$ thick croconic acid thin film, with a $150 \mathrm{~nm}$ spacing between electrodes and for diminished nonvolatility.

This research was supported by the National Science Foundation through NSF-Chem 1565692 (G. Hao, A. Mosey, R. Cheng, and P. A. Dowben) and the Nebraska MRSEC (DMR1420645) (X. Jiang, X. Xu, X. Zhang, J. Zhang, and A. Yost). The use of the Advanced Light Source, Lawrence Berkeley National Laboratory, was supported by the U.S. Department of Energy (DOE) under Contract No. DE-AC02-05CH11231. The lithography was funded in part by Sandia's LDRD Program and was performed, in part, at the Center for Integrated Nanotechnologies, a U.S. DOE Basic Energy Sciences user facility. Sandia National Laboratories is managed and operated by National Technology \& Engineering Solutions of Sandia, LLC, a wholly owned subsidiary of Honeywell International, Inc., for the U.S. Department of Energy's National Nuclear Security Administration under Contract No. DE-NA0003525. The views expressed in the article do not necessarily represent the views of the U.S. Department of Energy or the United States Government. The authors acknowledge helpful discussions with B. Doudin and A. Enders.

\section{REFERENCES}

${ }^{\top}$ A. Cornia and P. Seneor, Nat. Mater. 16, 505 (2017).

${ }^{2}$ D. Aravena and E. Ruiz, J. Am. Chem. Soc. 134, 777 (2012).

${ }^{3}$ T. G. Gopakumar, F. Matino, H. Naggert, A. Bannwarth, F. Tuczek, and R. Berndt, Angew. Chem., Int. Ed, 51, 6262 (2012).

${ }^{4}$ W. Kuch and M. J. Bernien, Condens. Matter 29, 023001 (2017).

${ }^{5}$ E. Ludwig, H. Naggert, M. Kalläne, S. Rohlf, E. Kröger, A. Bannwarth, A. Quer, K. Rossnagel, L. Kipp, and F. Tuczek, Angew. Chem., Int. Ed. 53, 3019 (2014).

${ }^{6}$ T. Mahfoud, G. Molnár, S. Bonhommeau, S. Cobo, L. Salmon, P. Demont, H. Tokoro, S.-I. Ohkoshi, K. Boukheddade, and A. Bousseksou, J. Am. Chem. Soc. 131, 15049 (2009).
${ }^{7}$ T. Mahfoud, G. Molnár, S. Cobo, L. Salmon, C. Thibault, C. Vieu, P. Demont, and A. Bousseksou, Appl. Phys. Lett. 99, 053307 (2011).

${ }^{8}$ T. Miyamachi, M. Gruber, V. Davesne, M. Bowen, S. Boukari, L. Joly, F. Scheurer, G. Rogez, T. K. Yamada, P. Ohresser, E. Beaurepaire, and W. Wulfhekel, Nat. Commun. 3, 938 (2012).

${ }^{9}$ F. Prins, M. Monrabal-Capilla, E. A. Osorio, E. Coronado, and H. S. van der Zant, J. Adv. Mater. 23, 1545 (2011).

${ }^{10}$ A. Pronschinske, Y. Chen, G. F. Lewis, D. A. Shultz, A. Calzolari, N. B. Nardelli, and D. B. Dougherty, Nano Lett. 13, 1429 (2013).

${ }^{11}$ A. Rotaru, I. Y. A. Gural'skiy, G. Molnar, L. Salmon, P. Demont, and A. Bousseksou, Chem. Commun. 48, 4163 (2012).

${ }^{12}$ A. Rotaru, J. Dugay, R. P. Tan, I. A. Gural'skiy, L. Salmon, P. Demont, J. Carrey, G. Molnar, M. Respaud, and A. Bousseksou, Adv. Mater. 25, 1745 (2013).

${ }^{13}$ E. Ruiz, Phys. Chem. Chem. Phys. 16, 14 (2014).

${ }^{14}$ X. Zhang, P. S. Costa, J. Hooper, D. P. Miller, A. T. N'Diaye, S. Beniwal, X. Jiang, Y. Yin, P. Rosa, L. Routaboul, M. Gonidec, L. Poggini, P. Braunstein, B. Doudin, X. Xu, A. Enders, E. Zurek, and P. A. Dowben, Adv. Mater. 29, 1702257 (2017).

${ }^{15}$ M. Gruber, V. Davesne, M. Bowen, S. Boukari, E. Beaurepaire, W. Wulfhekel, and T. Miyamachi, Phys. Rev. B 89, 195415 (2014).

${ }^{16}$ M. Gruber, T. Miyamachi, V. Davesne, M. Bowen, S. Boukari, W. Wulfhekel, M. Alouani, and E. Beaurepaire, J. Chem. Phys. 146, 092312 (2017).

${ }^{17}$ M. G. Cowan, J. Olguín, S. Narayanaswamy, J. L. Tallon, and S. Brooker, J. Am. Chem. Soc. 134, 2892 (2012).

${ }^{18}$ X. Zhang, A. T. N'Diaye, X. Jiang, X. Zhang, Y. Yin, X. Chen, X. Hong, X. Xu, and P. A. Dowben, Chem. Commun. 54, 944 (2018).

${ }^{19}$ X. Zhang, T. Palamarciuc, J.-F. Létard, P. Rosa, E. Lozada, F. Torres, L. G. Rosa, B. Doudin, and P. A. Dowben, Chem. Commun. 50, 2255 (2014).

${ }^{20}$ X. Jiang, H. Lu, Y. Yin, X. Zhang, X. Wang, L. Yu, Z. Ahmadi, P. S. Costa, A. D. DiChiara, X. Cheng, A. Gruverman, A. Enders, and X. Xu, Appl. Phys. Lett. 109, 102902 (2016)

${ }^{21}$ J.-F. Létard, P. Guionneau, L. Rabardel, J. A. K. Howard, A. E. Goeta, D. Chasseau, and O. Kahn, Inorg. Chem. 37, 4432 (1998).

${ }^{22}$ T. Palamarciuc, J. C. Oberg, F. El Hallak, C. F. Hirjibehedin, M. Serri, S. Heutz, J.-F. Létard, and P. Rosa, J. Mater. Chem. 22, 9690 (2012).

${ }^{23}$ A. Pronschinske, R. C. Bruce, G. Lewis, Y. Chen, A. Calzolari, M. Buongiorno-Nardelli, D. A. Shultz, W. You, and D. B. Dougherty, Chem. Commun, 49, 10446 (2013).

${ }^{24}$ N. Moliner, L. Salmon, L. Capes, M. C. Muñoz, J.-F. Létard, A. Bousseksou, J.-P. Tuchagues, J. J. McGarvey, A. C. Dennis, M. Castro, R. Burriel, and J. A. Real, J. Phys. Chem. B 106, 4276 (2002).

${ }^{25}$ B. Warner, J. C. Oberg, T. G. Gill, F. El Hallak, C. F. Hirjibehedin, M. Serri, S. Heutz, M. A. Arrio, P. Sainctavit, M. Mannini, G. Poneti, R. Sessoli, and P. Rosa, J. Phys. Chem. Lett. 4, 1546 (2013).

${ }^{26} \mathrm{X}$. Zhang, S. Mu, G. Chastanet, N. Daro, T. Palamarciuc, P. Rosa, J.-F. Létard, J. Liu, G. E. Sterbinsky, D. A. Arena, C. Etrillard, B. Kundys, B. Doudin, and P. A. Dowben, J. Phys. Chem. C 119, 16293 (2015).

${ }^{27}$ X. Zhang, T. Palamarciuc, P. Rosa, J.-F. Létard, B. Doudin, Z. Zhang, J. Wang, and P. A. Dowben, J. Phys. Chem. C 116, 23291 (2012).

${ }^{28}$ S. Maji, P. Kanti Sarkar, L. Aggarwal, S. K. Ghosh, D. Mandal, G. Sheet, and S. Acharya, Phys. Chem. Chem. Phys. 17, 8159 (2015).

${ }^{29}$ J. A. Real, M. C. Muñoz, J. Faus, and X. Solans, Inorg. Chem. 36, 3008 (1997).

${ }^{30}$ X. Jiang, X. Wang, G. Hao, X. Zhang, L. Yu, A. J. Yost, A. D. DiChiara, A. T. N'Diaye, X. Cheng, J. Zhang, P. A. Dowben, and X. Xu, "Interface-mediated bistabilty in a spin crossover molecular complex," Appl. Phys. Lett. (submitted).

${ }^{31}$ P. Nachimuthu, J. H. Underwood, C. D. Kemp, E. M. Gullikson, D. W. Lindle, D. K. Shuh, and R. C. C. Perera, AIP Conf. Proc. 705, 454-457 (2004).

${ }^{32}$ H. Qu, W. Yao, T. Garcia, J. Zhang, A. V. Sorokin, S. Ducharme, P. A. Dowben, and V. M. Fridkin, Appl. Phys. Lett. 82, 4322 (2003). 